\title{
Exploring the Influential Factors of Manufacturers' Initial Intention in Applying for the Green Mark EcoLabel in Taiwan
}

\author{
Shu-Chiang Lin', Satria Fadil Persada', Reny Nadlifatin', Hsiang-Yu Tsai', and Chih-Hsing Chu, 1,2, \\ 1 Department of Industrial Management, National Taiwan University of Science and Technology, 43, Keelung Rd, Da'an Dist, Taipei, 106, Taiwan \\ 2 Department of Industrial Engineering and Engineering Management, National Tsing Hua University, 101, Section 2, Kuang-Fu Road, Hsinchu, 300, Taiwan \\ \# Corresponding Author / E-mail: chchu@ie.nthu.edu.tw, TEL: +886-3-5742698, FAX: +886-3-5722685
}

KEYWORDS: Green mark eco-label, Manufacturers, Initial intention, Application process, Structural equation modeling

\begin{abstract}
The Green Mark eco-label constitutes an essential program introduced by Taiwan's Environmental Protection Administration to support environmental protection. In the manufacturing industry, the Green Mark eco-label is intended to enable differentiating between manufacturers that apply green processes and those that do not. This paper presents an assessment model for identifying manufacturers' initial intention to apply the Green Mark eco-label. The model was derived from the certification process flow. A total of 200 structured questionnaires were distributed to manufacturers in Taiwan, and 172 responses were retrieved. The model was analyzed by applying structural equation modeling, and the correlation of review process and end certification process exhibited the strongest correlation. Improving the document verification stage is highly likely to increase the overall initial intention ofmanufacturers to participate in the Green Mark eco-label program. The overall certification process contributed $16 \%$ to the total initial intention of manufacturers to apply the Green Mark eco-label to their products.
\end{abstract}

\section{NOMENCLATURE}

$\beta=$ Correlation variable between factors

$\mathrm{p}=$ Significance value

\section{Introduction}

The manufacturing industry is currently facing the challenge of reducing negative environmental impacts. Numerous factors contribute to environmental degradation, such as carbon dioxide emissions, unreprocessable wastes, and unrecyclable end products. To protect the environment, governments and environmental protection groups worldwide have suggested implementing green and sustainable manufacturing processes, and indicating the environmental friendliness of these processes on product labels.

Numerous countries have initiated environmental labeling to encourage the use of green processes; examples include the Ecomark,
GreenLabel, and Green Mark programs in Japan, Singapore, and Taiwan, ${ }^{1}$ respectively. In Taiwan, the Environmental Protection Administration (EPA) provides the guidelines and certifies the Green Mark program for manufacturers applying green processes. Subsequently, manufacturers can affix the Green Mark eco-label to their end products, which is intended to show their environmental concern and inspire both end customers and other manufacturers. However, not all manufacturers are aware of this program or realize the impact of their environmental processes on the environment. ${ }^{2}$

Numerous studies have suggested ${ }^{3}$ evaluating the influence of behavioral approaches on raising awareness of environmental issues. Bamberg and Moser, ${ }^{4}$ Fraj and Martinez, ${ }^{5}$ and Hansla et al. ${ }^{6}$ focused on the behavior of individuals and citizens, whereas few studies have examined manufacturers' perspectives and attitudes toward green behavior. ${ }^{7,8}$ This study is the first to investigate Taiwanese manufacturers' behavior regarding the application of the Green Mark eco-label.

This study proposes an evaluation model for the Green Mark ecolabel application process that enables determining manufacturers' initial intention (II) to participate in eco-label procedures. Relevant data were 
collected from Taiwanese manufacturers and analyzed using structural equation modeling (SEM). This study determines the influential factor and identifies the overall degree of contribution of the certification process on manufacturers' II in applying for the Green Mark eco-label.

\section{Taiwan Green Mark Eco-Label}

Taiwan's EPA launched the Green Mark eco-label in 1992. The program aims to encourage manufacturers to engage in green processes. The program is one of the go-green public policies that attempt to reduce the $\mathrm{CO}_{2}$ emissions induced by product and service life cycle activities. A positive achievement of adopting green processes was that $\mathrm{CO}_{2}$ emission was reduced by 23.59 million tonnes and exceeded 32 percent of the initial targets between years 2010 and $2013 .{ }^{9}$ In supporting this program, Taiwan government not only provided trainings as well as awards to green products, ${ }^{10}$ but also implemented a green procurement policy in public sectors since 2002. ${ }^{11}$ Through implementation of this policy, the government employees started to use green products in their daily jobs and subsequently attracted manufacturing companies to produce environmental-friendly products to meet this massive demand. The Green Mark logo (Fig. 1) is affixed to products labels to show consumers that a company employed green process(es) in manufacturing them. Through the work of the Environment and Development Foundation (EDF), the certification process has been applied to nearly 6000 products in 112 product categories, including cleaning, energy saving, IT products, office supplies, and construction material. ${ }^{10}$ In the fourth quarter of 2013, $315^{8}$ Taiwanese local manufacturers applied the Green Mark eco-label to their products.

To use the eco-label on products, manufacturers must complete the Green Mark eco-label certification process. ${ }^{12}$ Manufacturers can apply for the eco-label by submitting relevant manufacturing-related documents to the EDF using an online application system (OAS). The submitted documents are verified by an EDF committee that deliberates whether productions processes satisfy green process criteria. Generally, EDF provides the "environmentally benign criteria in a product if it produces less environmental impact than similar product and does not bring any adverse effects on health and safety. ${ }^{1}$ More specifically, the individual product and category must meet certain qualitative evaluation criteria (e.g., in the office supplies category, mercurycontaining components in batteries must be replaced with mercury-free components). Document verification (DV) requires 7 days and a company has 14 days to update or furnish additional documents if necessary. The EDF frequently conducts on-site investigations to
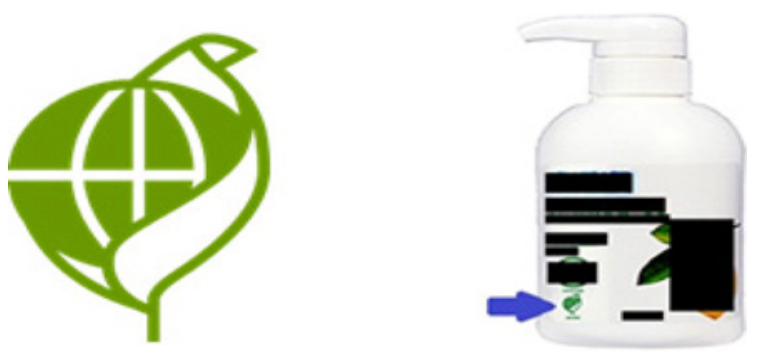

Fig. 1 Taiwan's Green Mark eco-label (left) and an example of the Green Mark eco-label on a product (right) monitor the materials used for preventing label misuse. Approximately 1 month is required for field observations (FOs) and material monitoring. The data obtained from DV and FOs will be used as the source of review process (RP). Subsequently, an EDF review committee, comprising representatives from government and nongovernmental organizations, academia, manufacturing associations, and other stakeholders, reviews the documents. They reexamine relevant documents and subsequently determine whether the application satisfies the eligibility criteria. The assessment process requires less than 5 days, after which the EDF apprises the company of the outcome. If the application is approved, the end certification process (ECP) requires 3 working days, after which the Green Mark certificate is issued. Subsequently, a manufacturer can use the Green Mark eco-label on the certified products.

\section{Exploration Model}

This study focused on evaluating the factors in the certification process that affect the II of manufacturers applying for the Green Mark eco-label. The six core factors, constructed according to the certification process flow (Fig. 2), comprise the OAS, DV, FO, review process (RP), ECP, and a company's II. According to the process for behavior assessment, the following hypotheses are proposed:

$\mathrm{H} 1$ : The perceived OAS is positively related to the perceived DV in applying for the Green Mark eco-label.

$\mathrm{H} 2$ : The perceived DV is positively related to the perceived FO in applying for the Green Mark eco-label.

H3: The perceived DV is positively related to the perceived RP in applying for the Green Mark eco-label.

H4: The perceived FO is positively related to the perceived RP in applying for the Green Mark eco-label.

H5: The perceived RP is positively related to the perceived ECP in applying for the Green Mark eco-label.

H6: The perceived ECP is positively related to manufacturers' II in applying for the Green Mark eco-label.

\section{Research Methodology}

This study built an assessment model and developed a questionnaire

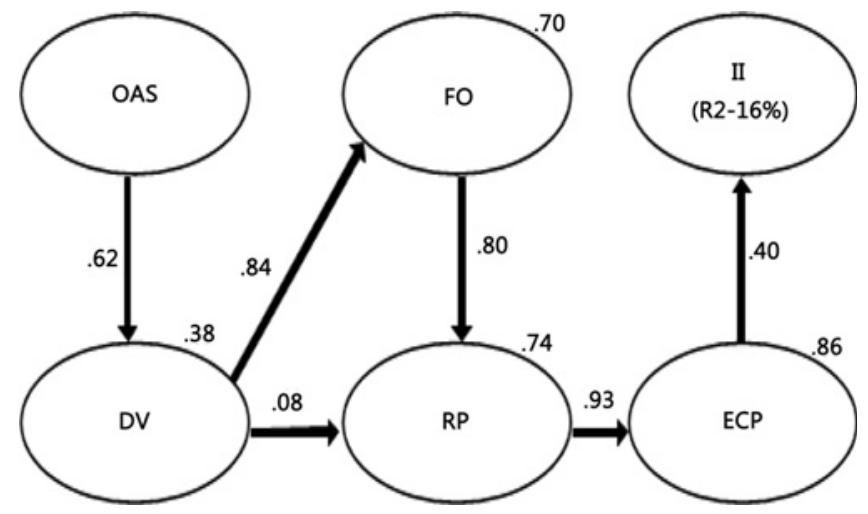

Fig. 2 Green Mark eco-label evaluation model 
Table 1 Descriptive statistic

\begin{tabular}{|c|c|c|c|}
\hline Factors & Questions & Mean & Stdev \\
\hline \multirow[t]{3}{*}{ OAS } & $\begin{array}{l}\text { Green Mark eco-label online } \\
\text { application system is stable and no error } \\
\text { appears in using it. }\end{array}$ & 3.27 & 1.06 \\
\hline & $\begin{array}{l}\text { Green Mark eco-label online } \\
\text { application system is convenient to be } \\
\text { used. It shows the simplicity of } \\
\text { uploading a file and no repeat steps } \\
\text { appeared. }\end{array}$ & 3.65 & 0.98 \\
\hline & $\begin{array}{l}\text { Green Mark online application system } \\
\text { is simple and easy to use. }\end{array}$ & 3.25 & 1.04 \\
\hline \multirow[t]{3}{*}{ DV } & $\begin{array}{l}\text { The verification agency is nice, the } \\
\text { agency frequently helps to correct the } \\
\text { document filing process and notify } \\
\text { about any information to the vendor. }\end{array}$ & 4.14 & 0.88 \\
\hline & $\begin{array}{l}\text { The verification agency is good, the } \\
\text { agency frequently notifies the } \\
\text { manufacturer about the additional } \\
\text { documents needed to update the content } \\
\text { revision. }\end{array}$ & 4.19 & 0.79 \\
\hline & $\begin{array}{l}\text { The verification agency is helpful, the } \\
\text { agency rarely delayed the document } \\
\text { checklist in seven days and rarely } \\
\text { delayed the substance document } \\
\text { checking in one month. }\end{array}$ & 4.13 & 0.81 \\
\hline \multirow[t]{3}{*}{$\mathrm{FO}$} & $\begin{array}{l}\text { Field observation is goodly conducted, } \\
\text { where only in some special conditions } \\
\text { that the field auditor verifies the whole } \\
\text { process and it does not disturb the } \\
\text { production process. }\end{array}$ & 4.14 & 0.83 \\
\hline & $\begin{array}{l}\text { Field observation is decently } \\
\text { performed, where they charge with the } \\
\text { reasonable price for field auditor. }\end{array}$ & 3.75 & 0.97 \\
\hline & $\begin{array}{l}\text { Field observation is nicely carried, } \\
\text { where the verification unit is having a } \\
\text { good response to cooperate with } \\
\text { manufacture schedule. }\end{array}$ & 4.17 & 0.71 \\
\hline \multirow[t]{2}{*}{$\mathrm{RP}$} & $\begin{array}{l}\text { The review process is performed at the } \\
\text { accurate time, where five days are } \\
\text { conducted to review the result. }\end{array}$ & 4.23 & 0.68 \\
\hline & $\begin{array}{c}\text { The review process is performed in } \\
\text { precise time, where in possibly less than } \\
\text { one week estimation to review. }\end{array}$ & 4.20 & 0.70 \\
\hline \multirow[t]{2}{*}{ ECP } & $\begin{array}{l}\text { End certification process is nicely } \\
\text { performed, where after } 3 \text { days and paid } \\
\text { the fee then the company can own the } \\
\text { certificate. }\end{array}$ & 4.26 & 0.69 \\
\hline & $\begin{array}{l}\text { End certification process is well } \\
\text { conducted, where the content is } \\
\text { accurate in accordance with the aims. }\end{array}$ & 4.25 & 0.66 \\
\hline \multirow[t]{3}{*}{ II } & $\begin{array}{c}\text { The company will love to engage green } \\
\text { policy concepts and intent to do it. }\end{array}$ & 4.55 & 0.58 \\
\hline & $\begin{array}{l}\text { The company will like to perform clean } \\
\text { production from time to time in } \\
\text { responding the initiative of the } \\
\text { environmental movement. }\end{array}$ & 4.48 & 0.61 \\
\hline & $\begin{array}{l}\text { The company will want to perform } \\
\text { green initiative, where their routine } \\
\text { activties such as maintenance, safety } \\
\text { and health will be based on pro } \\
\text { environmental intention. }\end{array}$ & 4.54 & 0.54 \\
\hline
\end{tabular}

for collecting data. The structured questionnaire contained two sections. The first section featured questions regarding 16 observed variables for measuring six factors in the proposed model, representing manufacturers' assessment of each process: OAS, DV, FO, RP, ECP, and companies' II. A 5-point Likert scale was used in the questionnaire, ranging from 1 (strongly disagree) to 5 (strongly agree). The second section of the questionnaire recorded the company name, details of the person completing the questionnaire, and general comments regarding the procedures involved in applying for the Green Mark. The questionnaires were distributed to 200 companies between September 2013 and March 2014 through email, out of which 172 companies replied. The companies who completed the questionnaire were familiar with the Green Mark eco-label application procedures.

\section{Analysis Result}

The 172 collected questionnaires contained predominantly neutral to agree responses, with averages ranging from 3.25 to 4.55 (Table 1), indicating that most companies responded positively regarding most of the process.

SEM analysis was performed to evaluate the structural correlation between the interconnected factors. The reason why SEM was used because its ability to represent the underlying relations of sample data in a path diagram as well as to effectively analyze the multiple correlation problems. ${ }^{13}$ In the SEM analysis process, both data validity and model validty are considered as the required parameters. For data validity, some evaluations on factor loadings, Cronbach's á, composite reliability (CR), and average variance extracted (AVE) values were calculated to test the reliability and convergent validity of the dataset. Factor loadings were used to identify the weight and correlation values between questionnaire variables as observed indicators. An accurate representation of the dimensionality factors can be achieved when the load value is high. ${ }^{14}$ Cronbach's $\alpha$ reflects internal consistency among questions as constructed factors. ${ }^{15} \mathrm{CR}$ measures the reliability by providing a precise estimation using factor loadings in the constructed

Table 2 Questionnaire reliability and convergent validity result

\begin{tabular}{|c|c|c|c|c|c|}
\hline Factor & Item & $\begin{array}{c}\text { Factor } \\
\text { loadings }\end{array}$ & Cronbach's $\alpha$ & $\mathrm{CR}$ & AVE \\
\hline \multirow{3}{*}{ OAS } & OAS1 & 0.73 & \multirow{3}{*}{0.80} & \multirow{3}{*}{0.81} & \multirow{3}{*}{0.59} \\
\hline & OAS2 & 0.80 & & & \\
\hline & OAS3 & 0.77 & & & \\
\hline \multirow{3}{*}{ DV } & DV1 & 0.68 & \multirow{3}{*}{0.78} & \multirow{3}{*}{0.83} & \multirow{3}{*}{0.55} \\
\hline & DV2 & 0.71 & & & \\
\hline & DV3 & 0.83 & & & \\
\hline \multirow{3}{*}{ FO } & FO1 & 0.82 & \multirow{3}{*}{0.83} & \multirow{3}{*}{0.84} & \multirow{3}{*}{0.64} \\
\hline & $\mathrm{FO} 2$ & 0.69 & & & \\
\hline & FO3 & 0.88 & & & \\
\hline \multirow{2}{*}{$\mathrm{RP}$} & RP1 & 0.95 & \multirow{2}{*}{0.94} & \multirow{2}{*}{0.94} & \multirow{2}{*}{0.88} \\
\hline & RP2 & 0.94 & & & \\
\hline \multirow{2}{*}{ ECP } & ECP1 & 0.94 & \multirow{2}{*}{0.89} & \multirow{2}{*}{0.90} & \multirow{2}{*}{0.82} \\
\hline & ECP2 & 0.87 & & & \\
\hline \multirow{3}{*}{ II } & II1 & 0.79 & \multirow{3}{*}{0.73} & \multirow{3}{*}{0.89} & \multirow{3}{*}{0.89} \\
\hline & II2 & 0.84 & & & \\
\hline & II3 & 0.95 & & & \\
\hline
\end{tabular}


formula. ${ }^{16} \mathrm{AVE}$ is the average quantity of variance among the observed variables, describing a latent construct. ${ }^{17}$ Several studies have indicated that factor loadings, Cronbach's $\alpha, \mathrm{CR}$, and AVE must have minimal values of $0.7,{ }^{18,19} 0.7,{ }^{18} 0.6,{ }^{18}$ and $0.5,{ }^{18,20}$ respectively.

The experimental results regarding questionnaire reliability and convergent validity showed that the factor loadings of data verification 1 (DV1) and field observation 2 (FO2) slightly decreased; however, they were still 0.7 after rounding. Most questions surpassed the minimal requirement for reliability and convergent validity (Table 2). Hence, the tests were statistically satisfying.

The data exhibited high reliability and convergent validity and were subsequently used to test the proposed hypotheses using the influential model. The entire data were simulated using an SEM. The result of the SEM simulation model (Fig. 3) shows positive values for seven path correlations. OAS positively correlated with DV (value: 0.62 ), and DV positively correlated with FO and RP ( 0.84 and 0.08 , respectively). FO positively correlated with RP $(0.80)$, and RP positively correlated with ECP (0.93). ECP positively correlated with II (0.40). To test the model fit of this observation, the following fit parameters were used: goodness of fit (GFI), adjusted goodness of fit (AGFI), comparative fit index (CFI), and root mean square residual (RMR). The assessment results surpassed the minimal value, as shown in Table 3, which indicates that the model was sufficiently accurate.

The final measurement test was performed by measuring the significance of correlations among the factors. Because the sample size was relatively small ( $\mathrm{N} 400){ }^{23,24}$ this study used bootstrap tests as recommended by several researchers. The results are reported in Table 4 .

The significance test revealed that five of the six direct correlations exhibited high significance. All indirect correlations exhibited significant and positive values, confirming that the flows among factors were crucial, although the manufacturers did not fully consider this. The direct insignificant value between DV and RP $\left(\beta_{\mathrm{DV} \rightarrow \mathrm{RP}}=0.076\right)$ may be attributable to the manufacturers' belief that they could fail the RP despite clearing the document verification stage. The strongest correlation in the influential model was between RP and ECP

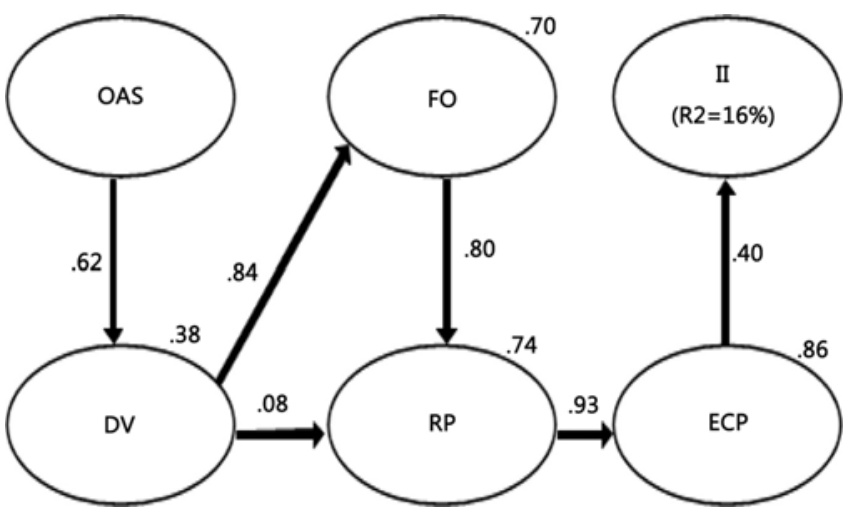

Fig. 3 Results of the Green Mark eco-label evaluation model

Table 3 Model fit result

\begin{tabular}{ccc}
\hline Model fit parameters & Influential model & Minimum value \\
\hline GFI & 0.86 & $\geq 0.80^{21}$ \\
\hline AGFI & 0.81 & $\geq 0.80^{21}$ \\
\hline CFI & 0.94 & $\geq 0.90^{21}$ \\
\hline RMR & 0.05 & $\leq 0.08^{22}$ \\
\hline
\end{tabular}

$\left(\beta_{\mathrm{RP} \rightarrow \mathrm{ECP}}=0.930\right)$, indicating that manufacturers tend to be concerned with the review during the final stages, because the review stage determines whether they receive the eco-label. Thus, the significance levels of the direct correlations confirmed five of the six hypotheses (Table 5).

Finally, according to the correlation simulation, the influential model contributes $16 \%(\mathrm{R} 2=16 \%)$ to the real situation, indicating that the certification process contributes $16 \%$ to the manufacturers' total II in applying for the Green Mark eco-label. Approximately $84 \%$ of manufacturers' II was influenced by factors external to the certification process. The findings reveal external factors beyond the certification process most related to manufacturers' initial intention in applying Green Mark eco-label. This condition might be caused by less concern about the benefits obtained from producing green products, such as benefits from government's promotion activity as well as the strength of label recognition by consumers to use green products. These two possible reasons were similarly identified by Wang et al., ${ }^{25}$ which attempted to understand the

Table 4 Significance ofthe correlations

\begin{tabular}{ccccc}
\hline \multirow{2}{*}{$\begin{array}{c}\text { Correlation between } \\
\text { factors }\end{array}$} & \multicolumn{2}{c}{ Direct } & \multicolumn{2}{c}{ Indirect } \\
\cline { 2 - 5 } & $(\alpha)$ & $(\mathrm{p})$ & $(\mathrm{a})$ & $(\mathrm{p})$ \\
\hline $\mathrm{DV} \leftarrow \mathrm{OAS}$ & 0.616 & $0.001^{* *}$ & - & - \\
\hline $\mathrm{FO} \leftarrow \mathrm{OAS}$ & - & - & 0.517 & $0.001^{* *}$ \\
\hline $\mathrm{RP} \leftarrow \mathrm{OAS}$ & - & - & 0.459 & $0.001^{* *}$ \\
\hline $\mathrm{ECP} \leftarrow \mathrm{OAS}$ & - & - & 0.427 & $0.001^{* *}$ \\
\hline $\mathrm{II} \leftarrow \mathrm{OAS}$ & - & - & 0.169 & $0.001^{* *}$ \\
\hline $\mathrm{FO} \leftarrow \mathrm{DV}$ & 0.839 & $0.001^{* *}$ & - & - \\
\hline $\mathrm{RP} \leftarrow \mathrm{DV}$ & 0.076 & 0.767 & 0.669 & $0.001^{* *}$ \\
\hline $\mathrm{ECP} \leftarrow \mathrm{DV}$ & - & - & 0.693 & $0.001^{* *}$ \\
\hline $\mathrm{II} \leftarrow \mathrm{DV}$ & - & - & 0.274 & $0.001^{* *}$ \\
\hline $\mathrm{RP} \leftarrow \mathrm{FO}$ & 0.797 & $0.007^{* *}$ & - & - \\
\hline $\mathrm{ECP} \leftarrow \mathrm{FO}$ & - & - & 0.742 & $0.008^{* *}$ \\
\hline $\mathrm{II} \leftarrow \mathrm{FO}$ & - & - & 0.293 & $0.007^{* *}$ \\
\hline $\mathrm{ECP} \leftarrow \mathrm{RP}$ & 0.930 & $0.003^{* *}$ & - & - \\
\hline $\mathrm{II} \leftarrow \mathrm{RP}$ & - & - & 0.367 & $0.003^{* *}$ \\
\hline $\mathrm{II} \leftarrow \mathrm{ECP}$ & 0.395 & $0.003^{* *}$ & - & - \\
\hline
\end{tabular}

**: p $0.01 ; *$ : p 0.05

Table 5 Results of the hypotheses according to the influential model

\begin{tabular}{cc}
\hline Hypothesis & Result \\
\hline $\begin{array}{c}\text { Perceived online application system (OAS) is positively } \\
\text { related to perceived document verification (DV) to apply } \\
\text { green mark eco-label }\end{array}$ & Accepted \\
\hline $\begin{array}{c}\text { Perceived document verification (DV) is positively related } \\
\text { to perceived field observation (FO) to apply green mark } \\
\text { eco-label }\end{array}$ & Accepted \\
\hline
\end{tabular}

Perceived document verification (DV) is positively related to perceived review process (RP) to apply green mark eco- Rejected label

Perceived field observation (FO) is positively related to perceived review process (RP) to apply green mark eco- Accepted label

Perceived review process (RP) is positively related to perceived end certification process (ECP) to apply green Accepted mark eco-label

Perceived end certification process (ECP) is positively related to company's initial intention (II) to apply green Accepted mark eco-label 
consumers' perspectives on purchasing green products. Accordingly, when the trend of using green products becomes more reputable, it may encourage both purchasing and producing green products.

\section{Conclusions}

The use of the Green Mark eco-label is highly recommended for improving manufacturing by incorporating sustainable processes; in addition, the label displays the degree of manufacturers' environmental awareness. This research elucidated Taiwanese manufacturers' II regarding adopting the Green Mark eco-label from a behavioral perspective. According to the results of the SEM simulation, five of six positive correlations were verified.

The findings reveal that the correlation between DV and RP is not significant. The DV and RP stages contribute insignificantly to the II. This situation can be overcome by performing a deep lean analysis and streamlining this process to transform it into a single verification process. The correlation between RP and ECP was the strongest. The behavioral assessment affirms that manufacturers are more concerned about ECP than they are about the other stages. Relevant information regarding the potential improvement of green processes should be provided to applicants during the ECP stage, after which the manufacturer receives the permission to use the Green Mark eco-label.

Finally, the application procedure contributes $16 \%$ of manufacturers' II to use the eco-label, and $84 \%$ of the factors are potentially external to the certification process. An exploration of additional factors external to the evaluation model, such as subjective norms, perceived behavior control, and additional factors that potentially increase manufacturers' II, are strongly recommended for future research to enable a deeper understanding of manufacturers' intentions.

\section{ACKNOWLEDGEMENT}

The authors would like to express the gratitude to companies who provides time and information for answering structured questionnaire used in this research.

\section{REFERENCES}

1. Davis, G. A., "Environmental Labeling Issues, Policies, and Practices Worldwide," U.S. Environmental Protection Agency, 1998.

2. Kuo, T. C., Huang, M.-L., Hsu, C. W., Lin, C. J., Hsieh, C.-C., et al., "Application of Data Quality Indicator of Carbon Footprint and Water Footprint," Int. J. Precis. Eng. Manuf.-Green Tech., Vol. 2, No. 1, pp. 43-50, 2015.

3. Pickett-Baker, J. and Ozaki, R., "Pro-Environmental Products: Marketing Influence on Consumer Purchase Decision," Journal of Consumer Marketing, Vol. 25, No. 5, pp. 281-293, 2008.

4. Bamberg, S. and Möser, G., "Twenty Years after Hines, Hungerford, and Tomera: A New Meta-Analysis of Psycho-Social Determinants of Pro-Environmental Behaviour," Journal of Environmental Psychology, Vol. 27, No. 1, pp. 14-25, 2007.

5. Fraj, E. and Martinez, E., "Ecological Consumer Behaviour: An Empirical Analysis," International Journal of Consumer Studies, Vol. 31, No. 1, pp. 26-33, 2007.

6. Hansla, A., Gamble, A., Juliusson, A., and Gärling, T., "Psychological Determinants of Attitude Towards and Willingness to Pay for Green Electricity," Energy Policy, Vol. 36, No. 2, pp. 768774, 2008.

7. Liu, X., Yang, J., Qu, S., Wang, L., Shishime, T., et al., "Sustainable Production: Practices and Determinant Factors of Green Supply Chain Management of Chinese Companies," Business Strategy and the Environment, Vol. 21, No. 1, pp. 1-16, 2012.

8. Lin, S-C., Tsai, H-Y., and Shen, T-Y., "An Investigation on the Influential Factors of Green Product Manufacturers' Experiences and Decisions to Apply for Eco-Label "Green Mark" in Taiwan," Proc. of the International Conference on Service Sciences and Innovation, 2014.

9. Department of Information Services, Executive Yuan, "Environmental Protection," http://www.ey.gov.tw/en/cp.aspx?n=CA C23AE43FB2D9FC (Accessed 7 September 2015)

10. Taiwan Environmental Protection Administration, "The Green Mark Program in Chinese Taipei," http://greenliving.epa.gov.tw/GreenLife /eng/E-GreenMark.aspx (Accessed 7 September 2015)

11. Taiwan Environmental Protection Administration, "Government Green Procurement Promotion Policy," http://greenliving.epa.gov.tw /GreenLife/eng/E-Government_Green_Procurement_Promotion_Policy. aspx (Accessed 7 September 2015)

12. Taiwan Environmental Protection Administration, "Green Mark Certification," http://greenliving.epa.gov.tw/GreenLife/eng/english.aspx (Accessed 7 September 2015)

13. McDonald, R. P. and Ho, M.-H. R., "Principles and Practice in Reporting Structural Equation Analyses,” Psychological Methods, Vol. 7, No. 1, p. 64, 2002.

14. Reyna, O. T., "Getting Started in Factor Analysis (Using Stata 10)," https://www.princeton.edu/ otorres/Factor.pdf (Accessed 7 September 2015)

15. Cronbach, L. J., "Coefficient Alpha and the Internal Structure of Tests,” Psychometrika, Vol. 16, No. 3, pp. 297-334, 1951.

16. Shook, C. L., Ketchen, D. J., Hult, G. T. M., and Kacmar, K. M., "An Assessment of the Use of Structural Equation Modeling in Strategic Management Research," Strategic Management Journal, Vol. 25, No. 4, pp. 397-404, 2004.

17. Farrell, A. M. and Rudd, J. M., "Factor Analysis and Discriminant Validity: A Brief Review of Some Practical Issues,” Anzmac, 2009.

18. Cheon, J., Lee, S., Crooks, S. M., and Song, J., "An Investigation of Mobile Learning Readiness in Higher Education Based on the Theory of Planned Behavior," Computers \& Education, Vol. 59, No. 3, pp. 1054-1064, 2012. 
19. Gefen, D., Straub, D., and Boudreau, M.-C., "Structural Equation Modeling and Regression: Guidelines for Research Practice," Communications of the Association for Information Systems, Vol. 4, No. 1, pp. 7, 2000.

20. Fornell, C. and Larcker, D. F., "Evaluating Structural Equation Models with Unobservable Variables and Measurement Error," Journal of Marketing Research, pp. 39-50, 1981.

21. Yu, J., Ha, I., Choi, M., and Rho, J., "Extending the Tam for a TCommerce," Information \& Management, Vol. 42, No. 7, pp. $965-$ 976, 2005.

22. Hooper, D., Coughlan, J., and Mullen, M., "Structural Equation Modelling: Guidelines for Determining Model Fit," Electronic Journal of Business Research Methods, Vol. 6, No. 1, pp. 53-60, 2008.

23. Lin, S.-C., Persada, S. F., and Nadlifatin, R., "A Study of Student Behavior in Accepting the Blackboard Learning System: A Technology Acceptance Model (TAM) Approach," Proc. of the IEEE $18^{\text {th }}$ International Conference on Computer Supported Cooperative Work in Design, pp. 457-462, 2014.

24. Nadlifatin, R., Razif, M., Lin, S-C., Persada, S.F., and Belgiawan, P. F., "An Assessment Model of Indonesian Citizens' Intention to Participate on Environmental Impact Assessment (EIA): A Behavioral Perspective," Proc. of the $5^{\text {th }}$ International Conference on Sustainable Future for Human Security, 2014.

25. Wang, M-Y., Lin, S-C., and Chang, C-Y., "An Investigation on the Influential Factors of Consumer Purchasing Decision for Green Products in Taiwan," Proc. of the International Conference on Service Sciences and Innovation, 2014. 